\title{
Disseminated Ochroconis gallopavum Infection in a Chronic Lymphocytic Leukemia: A Case Report and Review of the Literature on Hematological Malignancies
}

\author{
Noriyasu FuKushima, Kotaro MAnNEn, Sumiaki OKAMOTO, \\ Taro SHINOGI*, Katsutaro NiSHIMOTO** and Eisaburo SUEOKA
}

\begin{abstract}
Disseminated fungal infection is an important cause of morbidity and mortality among patients with hematological malignancies. Ochroconis gallopavum is a dematiaceous and thermotolerant fungus that causes opportunistic infections in immunocompromised hosts. About only 30 cases of this organism infection have been reported worldwide. We report a disseminated Ochroconis gallopavum infection in a B-cell chronic lymphocytic leukemia patient. In spite of intensive anti-fungal treatment, no improvement in the clinical condition was observed and the patient died $\mathbf{4}$ months after diagnosis of the infection. Ochroconis gallopavum infection is a potentially fatal disease in hematological malignancies.

(Internal Medicine 44: 879-882, 2005)
\end{abstract}

Key words: Ochroconis gallopavum, B-CLL

\section{Introduction}

Fungus infection is a common cause of opportunistic infections in hematological malignancies, especially lymphoid malignancies, where it is associated with underlying compromised host defenses. Among these fungal infections, Aspergillus, Candida spp. and Cryptococcus are the major causes. Ochroconis (O.) gallopavum is a dematiaceous and thermotolerant fungus isolated from hot spring (1) and thermal effluent from a nuclear reactor (2). O. gallopavum is a rare causative agent encountered in human infection, especially in immunocompromised hosts such as organ transplant patients (3). We report here the disseminated $O$. gallopavum infection in a case of B-cell chronic lymphocytic leukemia (CLL), and review 4 other reported cases.

\section{Case Report}

In 1999, a 66-year-old Japanese woman was diagnosed with B-CLL (clinical stage II by Rai classification) (8), when a complete blood count revealed marked lymphocytosis $\left(11.8 \times 10^{9} / l\right.$, predominantly mature lymphocytes) and systemic lymphadenopathy. She was given chemotherapy using various combined regimens (low dose $\mathrm{CHOP}$, fludarabin etc.), but complete remission was not achieved. In March 2003, she had been having continuous low grade fever without cough, and was admitted to our hospital. Physical examination revealed multiple superficial lymphadenopathies (max $4 \mathrm{~cm}$ in diameter), a slightly hard mass (about $3 \mathrm{~cm}$ in diameter), without pain, at the subcutis of her left internal femur, and body temperature not exceeding $39^{\circ} \mathrm{C}$. Although no wheeze or crackle was noted in her respiration, plain chest $\mathrm{X}$-ray and chest computed tomography scans showed some opacity confined to the left upper lobe (Fig. 1A). Magnetic resonance imaging revealed a high intensity mass with central low intensity area confined to the left internal femoral (Fig. 1B). Laboratory examination showed an elevated white blood cell count of $36.7 \times 10^{9} / l$ (neutrophils $4 \%$, lymphocytes $1.5 \%$, abnormal lymphocytes $94 \%$ ), low hemoglobin concentration of $9.0 \mathrm{~g} / \mathrm{dl}$ and low platelet count of $42 \times 10^{9} / \mathrm{l}$. CRP was $0.48 \mathrm{mg} / \mathrm{dl}$ (normal range, $0-0.3 \mathrm{mg} / \mathrm{dl}$ ), and $\beta$-D glucan was markedly elevated $(95.0 \mathrm{pg} / \mathrm{ml}$, normal range, under 11 $\mathrm{pg} / \mathrm{ml}$ ). Liver and renal functions were normal. Bronchoscopic examination and biopsy of femoral mass were performed. Infiltration of fungi showed dark-brown, thickwalled, ovoid or spherical spores (Fig. 2A, 2B), as observed in this biopsy specimen from the femoral mass. And, in cul-

From the Department of Internal Medicine, Faculty of Medicine, *the Department of Dermatology, Faculty of Medicine, Saga University, Saga and **Nagasaki Hospital of Japan Seamen Relief Association, Nagasaki

Received for publication August 5, 2004; Accepted for publication March 31, 2005

Reprint requests should be addressed to Dr. Noriyasu Fukushima, the Department of Internal of Medicine, Faculty of Medicine, Saga University, Nabeshima, Saga 849-8501 


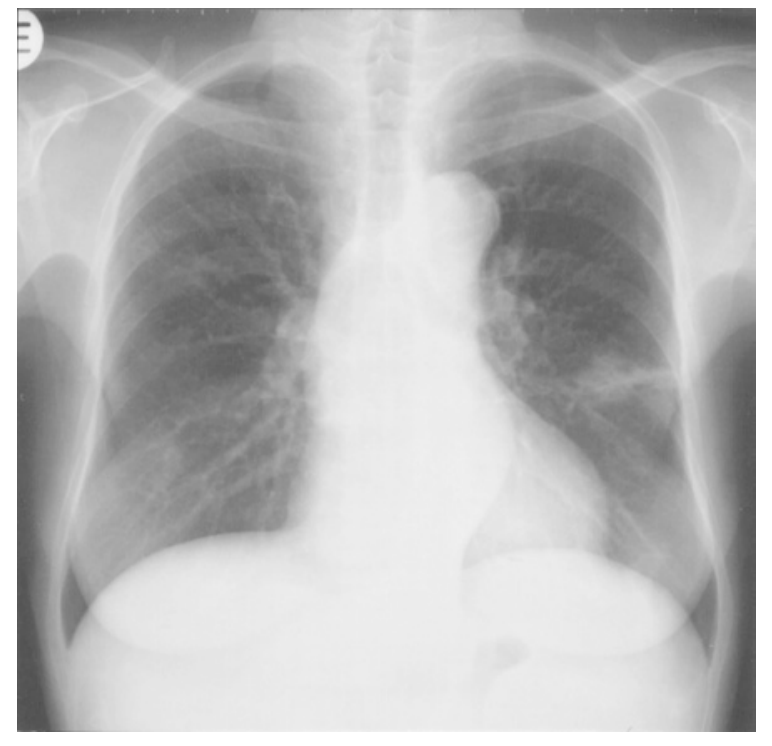

A

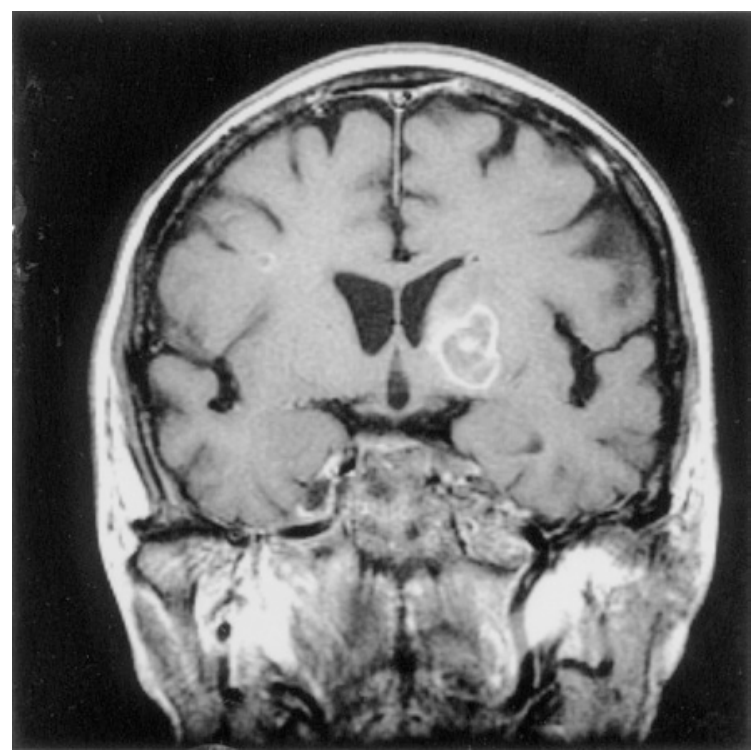

C

tivation of the sample obtained from bronchioalvelar lavage and the femoral mass, black fungi on potato dextrose agar grew relatively fast and formed flat, brownish and velvety colonies. Microscopically, these hyphae were hyaline to brownish. Conidia, borne on the tip of short conidiogenous cells, were two-celled, larger at apical cell, and constricted at septum (Fig. 2C). From these findings, the fungus was identified as Ochroconis gallopavum. The patient was given amphotericin-B at a dose of $0.75-1 \mathrm{mg} / \mathrm{kg} / \mathrm{day}$ by intravenous drip infusion, but since the opacities in her chest were growing, we added flucytosine (5-FC) $(8 \mathrm{~g} / \mathrm{day}$, oral administration), itraconazole $(200 \mathrm{mg} /$ day, oral administration) or terbinafine $(125-250 \mathrm{mg} / \mathrm{day}$, oral administration) in addition to amphotericin B. In spite of the intensive anti-fungal

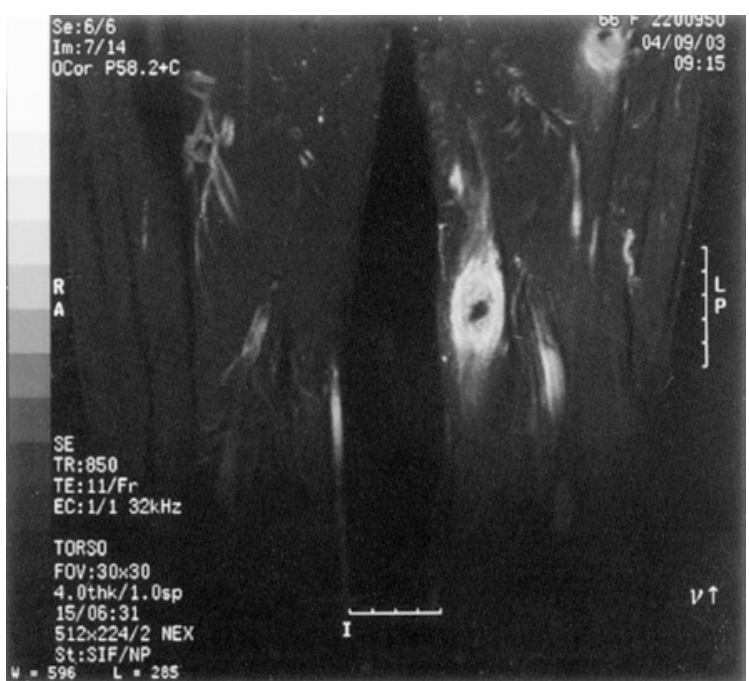

B

Figure 1. A) Posterioanterior radiograph shows some opacity involving the upper lobe of the left lung. B) Femoral MRI shows two ringed enhanced masses in the sartorius muscle and upper femoral muscle. C) Brain MRI shows a ringed enhaced mass at the thalamus. This finding is compatible with brain abscess.

treatment, the lung abscesses progressed and brain abscesses (Fig. 1C) developed. She died of brain abscesses in August 2003, 4 months after diagnosis of the causative fungus. Her autopsy was not performed.

\section{Discussion}

O. gallopavum (Synonyms: Dactylaria gallopavum, Dactylaria constricta var. gallopavum, Diplorhinotrichum gallopavum) is a thermotolerant and phaeohyphomycosis generally isolated from the environment. The fungus grows in soil and decaying vegetation, and has been isolated from broiler house litter of fowl (3). The species is a relatively common agent of encephalitis in poultry (4), and has also 


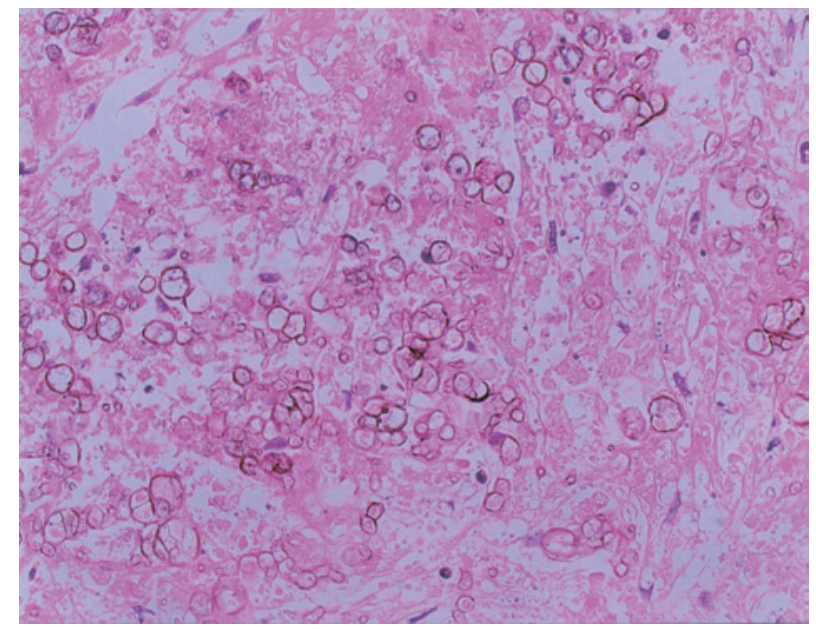

A

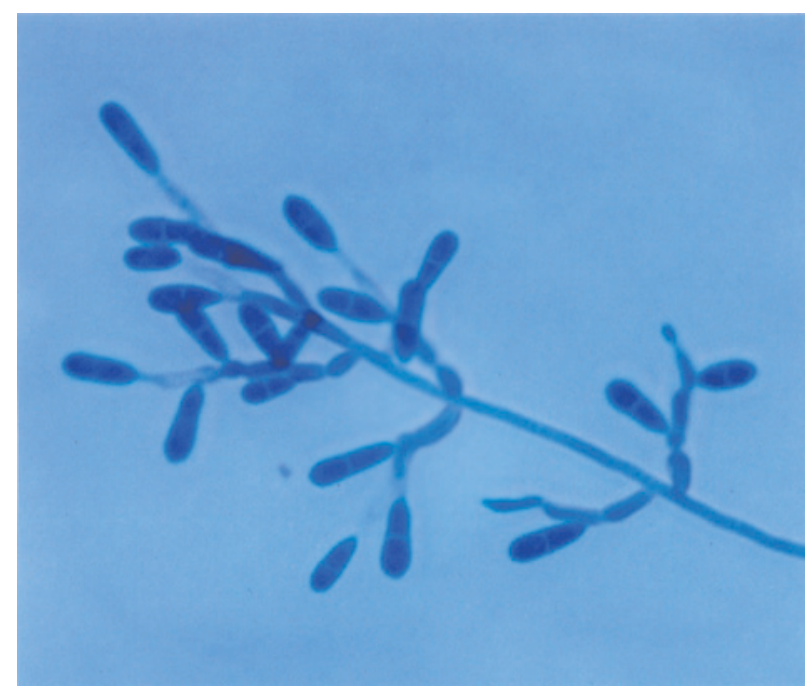

C

been isolated from effluents of acid hot springs and nuclear reactor. Optimal growth of $O$. gallopavum is obtained at $35^{\circ} \mathrm{C}$, tolerant to $40^{\circ} \mathrm{C}$. In the present case, the patient did not live near a broiler house or a hot spring, but engaged in gardening, suggesting that she might have been infected from soil. She had not been injured and it was hard to consider being transcutaneously infected. Her disease might follow inhalation and subsequent dissemination of conidia, such as muscular abscess and brain abscess (9).

This organism is rarely encountered in humans, and it more typically infects immunocompromised hosts, especially organ-transplanted patients $(5-7,10)$. There have been about 30 reported cases of $O$. gallopavum human infection, since the first report by Fukushiro et al on an AML patient in 1986 (11). Patients with hematological malignancies frequently suffer from fungal infections, such as Aspergillus, Candida or Cryptococcus, but among such patients, $O$. gallopavum infection is a very rare event, with only four cases of the

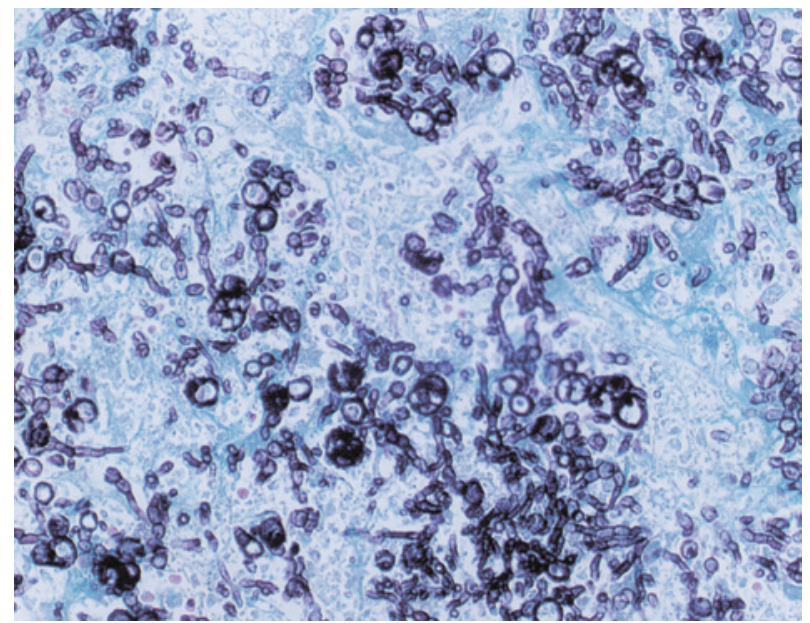

$\mathrm{B}$

Figure 2. A) HE stain, $\times 400$. Many dematiaceous fungi, appearing conspicuous dark brown, thick-walled, ovoid or spherical spores are observed. Inflammatory cell infiltration is slight. B) Grocott stain, $\times 400$. Hyphae of this organism are revealed by Grocott stain. C) lactophenol cotton blue stain, $\times 800$. These hyphae were hyaline to brownish. Conidia, borne on the tip of short conidiogenous cells, were two-celled, larger at the apical cell, and constricted at the septum.

infection reported (11-14). Table 1 presents a summary of the clinical features of the cases, which now number five, including the present case: Four cases were lymphoid malignancies and one was acute myeloblastic leukemia (AML). It is important to note that three of the five cases were CLL patients, since CLL patients often receive purine analogues resulting in persistent T-cell lymphocytopenia. The agents particularly affect CD4 positive $\mathrm{T}$ cells, which induce defect of $\mathrm{T}$ cell-mediated immunity similar to defects following treatment with immunosuppressive drug after organ transplantation. Thus, the persistent impairment of cell-mediated immunity might be associated with $O$. gallopavum infection, although other factors for the host immunity have been suggested. Furthermore, CLL patients may be more likely to have contact with $O$. gallopavum than those with other hematological malignancies, because of the long and indolent clinical course of their disease.

In terms of prognosis, all patients with the disseminated 
FUKUSHIMA et al

Table 1. Summary of Ochroconis gallopavum Infection in Patients of Hematological Disease

\begin{tabular}{lcllll}
\hline \multicolumn{1}{c}{ Reference } & Age/Sex & Underlying condition & \multicolumn{1}{c}{ Medical site } & Antifungal therapy & Outcome \\
\hline Present case & 66/F & B-CLL & lung, soft tissue, brain & AMPH-B, ITCZ, 5-FC & Death \\
Bowyer et al (14) & 69/M & CLL & left eye & AMPH-B, Flu, ITCZ & Death \\
Sides et al (13) & 60/M & malignant lymphoma & brain & AMPH-B, 5-FC & Death \\
Terreni et al (12) & 62/M & T-CLL diabetes mellitus & multiple organs & None noted & Death \\
Fukushiro et al (11) & 58/F & AML & skin & surgion, 5-FC & Successful \\
\hline
\end{tabular}

AMPH-B: amphotericin B, 5-FC: flucytocine, Flu: fluconazole, ITCZ: itriconazole.

infection died due to the involvement of this organism. Most disseminated infected patients were in a state of markedly impaired host defense associated with progression of underlying diseases, resulting in the high mortality rate. One AML patient was the only survivor among the hematological malignancies, and successful treatment was achieved by resection of the lesion. Among the 30 cases reported, most survivors had localized and resectable lesions (9, 10). Although there is no definitive treatment for dactylariosis, Kralovic et al recommended surgical excision, when possible, in combination with amphotericin B as the first line therapy for systemic phaeohyphomycosis (15). Minimal inhibitory concentration for $O$. gallopavum is relatively low $(0.06-$ $0.5 \mathrm{microgram} / \mathrm{ml}$ for amphotericin B, 4 microgram $/ \mathrm{ml}$ for 5FC, $0.01-0.5 \mathrm{microgram} / \mathrm{ml}$ for itraconazole and $0.03-0.06$ microgram $/ \mathrm{ml}$ for terbinafine ) (16), whereas there have been few reports of treatment using amphotericin B, with or without itraconazole, yielding successful results (7-10). Itraconazole or 5-FC is another possible treatment when amphotericin $\mathrm{B}$ induces intolerant toxicity. In the present case, surgery was not an option because the patient was initially diagnosed with the disseminated disease. We started antifungal chemotherapy using agents, including amphotericin B, itraconazole and terbinafine, but no remarkable effect was obtained. CLL did not progress during the treatment, but the patient died, probably due to central nervous system infiltration of this organism.

O. gallopavum infection is a rare - but almost invariably fatal- disease, especially for patients with a hematological malignancy. This infection is not curable by the existing antifungus agents, if the lesion is not resectable. It is necessary to develop a more effective drug for this organism, in the future.

Acknowledgements: We thank Dr. Hirashima for his useful advice. This work was supported in part by the following Grants in Aid for Cancer

Research: Special Cancer Research, from the Ministry of Education, Science, Sports and Culture, Japan.

\section{References}

1) Tansey MR, Brock TD. Dactylaria gallopava, a cause of avian encephalitis, in hot spring effluents, thermal soils and self-heated coal waste piles. Nature 242: 202-203, 1973.

2) Rippon JW, Gerhold R, Heath M. Thermophillic and thermotolerant fungi isolated from the thermal effluent of nuclear power generating reactors: dispersal of human opportunistic and veterinary pathogenic fungi. Mycopathologia 70: 169-179, 1980.

3) Waldrip DW, Padhye AA, Ajello L, Ajello M. Isolation of Dactylaria gallopava from broiler-house litter. Avian Dis 18: 445-451, 1974.

4) Blalock HG, Georg LK, Derieux WT. Encephalitis in turkey poults due to Dactylaria (Diplorhinotrichum) gallopava-a case report and its experimental reproduction. Avian Dis 17: 197-204, 1973.

5) Singh N, Chang FY, Gayowski T, Marino IR. Infections due to dematiaceous fungi in organ transplant recipients: case report and review. Clin Infect Dis 24: 369-374, 1997.

6) Wang TK, Chiu W, Chim S, Chan TM, Wong SS, Ho PL. Disseminated ochroconis gallopavum infection in a renal transplant recipient: the first reported case and a review of the literature. Clin Nephrol $\mathbf{6 0}$ : 415-423, 2003.

7) Vukmir RB, Kusne S, Linden $P$, et al. Successful therapy for cerebral phaeohyphomycosis due to Dactylaria gallopava in a liver transplant recipient. Clin Infect Dis 19: 714-719, 1994.

8) Rai KR, Sawitsky A, Cronkite EP, Chanana AD, Levy RN, Pasternack BS. Clinical staging of chronic lymphocytic leukemia. Blood 46: 219234, 1975.

9) Odell JA, Alvarez S, Cvitkovich DG, Cortese DA, McComb BL. Multiple lung abscesses due to Ochroconis gallopavum, a dematiaceous fungus, in a nonimmunocompromised wood pulp worker. Chest 118: 1503-1505, 2000.

10) Jenney A, Maslen $M$, Bergin P, Tang SK, Esmore D, Fuller A. Pulmonary infection due to Ochroconis gallopavum treated successfully after orthotopic heart transplantation. Clin Infect Dis 26: 236-237, 1998.

11) Fukushiro R, Udagawa S, Kawashima Y, Kawamura Y. Subcutaneous abscesses caused by Ochroconis gallopavum. J Med Vet Mycol 24: 175-182, 1986.

12) Terreni AA, DiSalvo AF, Baker AS Jr, Crymes WB, Morris PR, Dowda H Jr. Disseminated Dactylaria gallopava infection in a diabetic patient with chronic lymphocytic leukemia of the T-cell type. Am J Clin Pathol 94: 104-107, 1990.

13) Sides EH 3rd, Benson JD, Padhye AA. Phaeohyphomycotic brain abscess due to Ochroconis gallopavum in a patient with malignant lymphoma of a large cell type. J Med Vet Mycol 29: 317-322, 1991.

14) Bowyer JD, Johnson EM, Horn EH, Gregson RM. Oochroconis gallopava endophthalmitis in fludarabine treated chronic lymphocytic leukaemia. Br J Ophthalmol 84: 117, 2000.

15) Kralovic SM, Rhodes JC. Phaeohyphomycosis caused by Dactylaria (human dactylariosis): report of a case with review of the literature. J Infect 31: 107-113, 1995.

16) de Hoog GS, Guarro J, Gené J, Figueras MJ. Atlas of Clinical Fungi; 2nd ed. Utrecht: Centraal Bureau voor Schimmelcultures/Reus: Universitat Rovira i Virgili, 2000: 782-783. 